\title{
SAÚDE MENTAL DE CRIANÇAS NO CONTEXTO ESCOLAR
}

\section{ARTIGO ORIGINAL}

FIGUEREDO, Alziane Evelyn dos Santos ${ }^{1}$, ABREU, Regimara Simão de ${ }^{2}$, SOUZA, Júlio César Pinto de ${ }^{3}$

FIGUEREDO, Alziane Evelyn dos Santos. ABREU, Regimara Simão de. SOUZA, Júlio César Pinto de. Saúde mental de crianças no contexto escolar. Revista Científica Multidisciplinar Núcleo do Conhecimento. Ano 06, Ed. 08, Vol. 05, pp. 86 103. Agosto de 2021. ISSN: 2448-0959, Link de acesso: https://www.nucleodoconhecimento.com.br/psicologia/criancas-no-contexto, DOI: 10.32749/nucleodoconhecimento.com.br/psicologia/criancas-no-contexto

\section{RESUMO}

Esta pesquisa teve como problema norteador entender a atuação do profissional de educação no contexto escolar que visa promover a saúde mental da criança, uma vez que a criança é merecedora de maior a atenção dos profissionais da saúde mental, pois o indivíduo começa a se construir desde a infância, por meio de suas relações com a família e outros grupos sociais dos ambientes que frequenta e convive. Buscando desvendar o problema norteador, esta investigação teve como objetivo primário discutir sobre a saúde mental infantil no âmbito escolar, utilizandose de uma pesquisa de procedimento bibliográfico e abordagem qualitativa. O material analisado nesta pesquisa foi obtido nas plataformas científicas Capes e Scielo. Os resultados mostram que o âmbito escolar é um dos espaços onde se consegue verificar prejuízos ou mesmo o adoecimento psíquico da criança, bem como é no âmbito escolar que se pode estabelecer ações de promoção e prevenção a saúde mental da criança, por meio dos profissionais da escola. Faz-se necessário,

\footnotetext{
${ }^{1}$ Graduanda em Psicologia. ORCID: 0000-0003-0650-7809

${ }^{2}$ Graduanda em Psicologia. ORCID: 0000-0002-4805-0308

${ }^{3}$ Mestre em psicologia. ORCID: 0000-0003-3622-1393
}

RC: 94805

Disponível em: https://www.nucleodoconhecimento.com.br/psicologia/criancas-nocontexto 
entretanto, que esses profissionais se capacitem para tal tarefa. Os resultados ainda apresentam os elementos do Sistema Único de Saúde que tratam da saúde mental das crianças. O ambiente escolar deve ser também um espaço de promoção e prevenção a saúde mental da criança.

Palavras chaves: saúde mental, criança, família, ambiente escolar.

\section{INTRODUÇÃO}

Segundo a Organização Mundial de Saúde (OMS, 2017), a ocorrência de pessoas com transtornos psíquicos tem aumentado, de forma considerável, em âmbito global. São vários os fatores atribuídos para esse aumento significativo, entre eles, fatores ambientais e socioculturais e genéticos.

Ao longo da última década houve um aumento do interesse, pela comunidade científica mundial, a respeito da saúde mental do indivíduo, em particular das crianças, em face da identificação de transtornos mentais nesse grupo. No Brasil, as políticas públicas direcionadas a saúde mental surgiram a partir da Lei n³.657/89, sancionada em abril de 2001, que dispõe sobre a proteção e os direitos das pessoas portadoras de transtornos mentais (DELGADO; GOMES; COUTINHO, 2001). Entretanto, a construção dessas políticas públicas deu-se de forma generalista, abarcando a população de forma ampla, não sendo consideradas as especificidades de alguns grupos sociais, como a saúde mental da criança. A generalização da saúde mental ocasionou uma atuação rudimentar e pouco atuante na saúde mental infantil.

Nesse sentido, as políticas de saúde mental incipientes são explicadas pela ênfase dada a saúde como um adoecimento físico somente. Na sociedade brasileira, a saúde, por muito tempo, ficou limitada ao adoecimento físico do indivíduo, sendo os casos de adoecimento psíquico estigmatizados ou rechaçados. Somente com a reforma psiquiátrica, o transtorno psiquiátrico deixou de ser algo de "louco" (e por isso deveria ser afastado da sociedade) e passou a ser visto como um indivíduo 
adoecido. É valido citar que, mesmo com essa mudança de perspectiva ainda se mantinham algumas reservas quanto aos transtornos mentais infantis.

Ademais, os estudos dos transtornos psiquiátricos infantis eram direcionados, na sua maioria, para os transtornos psiquiátricos do neurodesenvolvimento, desconsiderando-se os transtornos mentais leves. Esse entendimento acompanhava o senso comum da sociedade que não considerava a possibilidade de uma criança ter algum problema psicológico como depressão, ansiedade e estresse, afinal "eram só crianças". Entretanto, os estudos direcionados a saúde mental indicaram uma ampla gama de transtornos psiquiátricos leves em crianças os quais podem afetar o desempenho de atividades consideradas normais para essa fase do desenvolvimento, nos diversos espaços que ela convive.

Durante o desenvolvimento do sujeito, comumente, surgem situações que desencadeiam sofrimento e que podem evoluir para um transtorno mental, e isso inclui a infância. Dentre os fatores estão os ambientais, os quais têm sido apontados como determinantes no desencadeamento de transtornos mentais e abalo na saúde mental infantil, causando assim adoecimento nas crianças (CID; MATSUKURA, 2014). Além disso, a família e a escola são os primeiros grupos sociais de convivência da criança e tem com eles a maior parte de suas experiências, percepções e compreensões de como "ser no mundo" (MATSUKURA; CID, 2008).

Cabe citar que, no convívio em grupos sociais citados pode surgir problemas ou situações de tensão e medo, principalmente na escola, lugar onde podem gerar transtornos mentais leves nas crianças, os quais quando não identificados, e se não tratados podem evoluir para transtornos mais severos, vindo a alterar suas relações interpessoais, comportamentos e procedimentos nesses espaços e em outros venha a conviver. Estudos mostram que, as crianças que possuem transtornos psíquicos apresentam maior probabilidade de terem dificuldades no contexto escolar, uma vez que a saúde mental do aluno, pode influenciar tanto no seu processo de 
desenvolvimento nos diversos espaços de relacionamento e convivência (D'ABREU; MARTURANO, 2010).

Ao tomar como parâmetro a linha de pesquisa expressa, estes autores primaram por responder o seguinte questionamento: De que forma a atuação do profissional de educação no contexto escolar visa promover a saúde mental da criança?

Nesse sentido, esta pesquisa busca estabelecer metas para responder a problemática, por isso, o objetivo é discutir sobre a saúde mental infantil no âmbito escolar e para alcançar esse objetivo o trabalho foi distribuído em três momentos: inicialmente, conceituou-se a "saúde mental" para, em seguida, discutir a atuação da escola na saúde mental da criança. Por fim, abordou-se sobre os espaços psicoterapêuticos infantis existentes e que podem ser usados na busca pela saúde mental da criança.

A relevância deste trabalho está na discussão sobre a saúde mental da criança, buscando compreender como os ambientes que ela frequenta nos primeiros anos de sua vida podem gerar os primeiros sintomas do adoecimento psíquico.

A ideia surgiu diante da necessidade discutir e ampliar os conhecimentos a respeito da saúde mental infantil, em face de a carência de estudos científicos, políticas voltadas para esta temática, buscando-se sensibilizar as famílias e profissionais do âmbito escolar para maior atenção da saúde mental em crianças nos primeiros anos de vida.

\section{PERCURSO METODOLÓGICO}

Esta pesquisa foi norteada por um procedimento bibliográfico e abordagem qualitativa. Para Gil et al. (2007), o estudo bibliográfico é desenvolvido através de fontes já publicadas, como livros, teses, dissertações, artigos, entre outros. A abordagem qualitativa foi necessária, visto que se coletou uma variedade de 
materiais e práticas interpretativas interligadas, visando compreender melhor o assunto em pauta (DENZIN; LINCOLN, 2006).

Para a realização da coleta de dados foram pesquisadas fontes científicas nas plataformas da Capes e Scielo, no período de 10 a 20 de março de 2021. O material bibliográfico abordado para análise foram artigos, trabalhos acadêmicos, pesquisas apresentadas em congresso e livros completos, todos encontrados nas plataformas científicas e na biblioteca do Centro Universitário FAMETRO-Manaus/AM. A fim de selecionar os trabalhos que tivessem relação com o tema, elegeu-se os descritores: escolar/escola, psicologia, Saúde mental e infantil/criança.

Os materiais encontrados foram classificados de acordo com data de publicação, país, narradores de áreas dos periódicos, sendo avaliado o fator impactante dos periódicos que mais publicaram a respeito do tema.

A análise do material foi conduzida, inicialmente pela seleção de trabalhos com títulos ligados ao assunto, sendo descartados os artigos repetidos, e, na sequência, foi feita a leitura dos resumos das obras. Nesta fase foram desconsiderados aqueles que não estavam alinhados a proposta desta pesquisa. Em uma terceira fase da análise dos dados, os trabalhos selecionados passaram por uma leitura reflexiva e interpretativa, na qual se construiu um panorama dos posicionamentos e perspectivas dos autores quanto ao tema em questão.

Os resultados obtidos favoreceram uma leitura assertiva e discussão objetiva, fazendo com que os materiais utilizados na discussão estivessem alinhados ao tema e que atendessem aos critérios de qualidade exigidos pela sociedade acadêmica (TREINTA et al., 2014).

A partir da análise das fontes foram selecionados 18 artigos, 1 Trabalho Acadêmico e 2 livros, sendo 19 em fontes em português e 2 em espanhol, para a composição da discussão do tema deste artigo. As fontes selecionadas para a discussão deste artigo foram produzidas no período de 2015 a 2021.

RC: 94805

Disponível em: https://www.nucleodoconhecimento.com.br/psicologia/criancas-nocontexto 


\section{RESULTADOS E DISCUSSÃO}

A discussão sobre o cuidado com a saúde mental da criança no âmbito escolar foi dividida em três momentos, seguindo a proposta dos objetivos da pesquisa e o problema norteador da pesquisa. Inicialmente abordou-se sobre a saúde mental e, na sequência discutiu-se sobre a atuação da escola na saúde mental da criança, seus elementos de prevenção e promoção, bem como fatores que podem levar ao adoecimento. O último tópico de discussão foi direcionado aos meios disponibilizados para a promoção e prevenção da saúde mental da criança.

\subsection{A SAÚDE MENTAL E SEUS PARADIGMAS}

O SUS têm um amplo conceito sobre saúde, incluído o cuidado à saúde mental, no entanto, esse entendimento não é "naturalizado pelos profissionais de saúde que compõe esse sistema", fazendo prevalecer o paradigma biomédico (GAINO et al., 2018). Por vezes os cuidados a saúde mental são deixados em segundo plano para focar na dimensão biológica.

O conceito de saúde mental é complexo, carregando suas influências nos contextos sociopolíticos e nos avanços de práticas em saúde. Sobre a Saúde mental, De Souza e Baptista (2017, p.209) argumentam que "[...] é o estado que permite ao indivíduo o aproveitamento total de suas capacidades cognitivas, afetivas e relacionais, o enfrentamento de dificuldades na vida, a contribuição para ações em sociedade e a produção no trabalho." A partir dessa argumentação verifica-se a complexidade da saúde mental, devido a diversidade de fatores que podem contribuir para a sua manutenção ou desestabilização.

Agilar (2018, p.12) argumenta que "a saúde mental no decorrer dos anos alcançou um olhar diferenciado na atenção psicossocial, ganhando espaço nas políticas públicas, tanto para a sociedade como para os profissionais da área". Na atual sociedade a saúde mental apresenta-se em evidência, fragilizada pela rotina e vida cotidiana do brasileiro. Ao se falar de saúde mental entende-se que "envolve a RC: 94805

Disponível em: https://www.nucleodoconhecimento.com.br/psicologia/criancas-nocontexto 
qualidade em como se lida com os próprios pensamentos, sentimentos e emoções durante o dia, nas atividades e nas relações com as pessoas, diariamente" (INSTITUTO AGENDA POSITIVA, 2020, p.01).

A partir da discussão, depreende-se que o conceito de saúde mental deve ser visto de maneira mais ampla, buscando-se sempre a historicidade da doença mental como um todo. Deve-se considerar, ainda, as manifestações desse adoecimento nos diversos espaços vividos pelo indivíduo, ressaltando que a saúde mental transpassa aspectos sociais, econômicos, culturais e ambientais. Dentro deste contexto surge uma discussão específica, a saúde mental da criança.

\subsection{A SAÚDE MENTAL DA CRIANÇA}

A saúde mental infantil é um tema complexo e multifacetado, visto que a sua compreensão e entendimento depende da análise de fatores comportamentais, sociais e emocionais (CID et al., 2019). Tais alterações devem ser acompanhadas por aqueles que estão próximos da criança, comumente os pais e professores, quando em idade escolar. Uma saúde mental equilibrada é importante para a criança, pois, de acordo com Santos e Celeri (2018, p.83) "os problemas de saúde mental interferem na qualidade das experiências precoces e, portanto, no desenvolvimento das potencialidades das crianças".

Aguiar (2018) argumenta que, atualmente é comum o encaminhamento de crianças, pelas escolas ou levadas por familiares, aos serviços de saúde em busca de auxílio, devido a alterações comportamentais como agressividade, humor explosivo e passividade e com sintomas de ansiedade, depressão. Em muitos desses casos, o psicodiagnóstico é direcionado para transtornos psiquiátricos leves.

Os quadros de sofrimento psíquico em crianças são mais delicados, pois elas não sabem exatamente o que estão sentindo e como lidar com seus sentimentos e emoções (CID et al., 2019). Tudo é novo para nesta fase, tanto os sentimentos desagradáveis que surgem perante uma situação de tensão quanto a forma de se

Disponível em: https://www.nucleodoconhecimento.com.br/psicologia/criancas-nocontexto 
portar em relação a essas sensações de desconforto. A partir desta percepção, fazse necessário o olhar atento para que, aos primeiros sintomas, sejam tomadas providencias oportunas.

Esse acompanhamento do desenvolvimento emocional e psicológico da criança se inicia no ambiente familiar (primeiro grupo social do indivíduo) e continua na escola, comumente, o segundo grupo social que a criança estabelece contato, depois do grupo familiar. Por isso, a saúde mental infantil deve ser acompanhada pelos pais e responsáveis, visto que a criança, por vezes, ainda não sabe lidar com determinadas emoções e sentimentos, acarretando problemas de saúde mental e interferindo nas experiências vivenciadas pelas crianças, prejudicando assim o desenvolvimento das potencialidades psicológicas, sociais e cognitivas da criança (SANTOS; CELERI, 2018).

Entretanto, nas famílias contemporâneas é comum pai e mãe trabalhem, tendo um contato restrito com seus filhos durante a semana. Nesses casos, as crianças que estão na fase escolar passam mais tempo com o professor e demais profissionais da escola do que com os pais, tornando o professor um elemento fundamental no acompanhamento da saúde mental da criança. Nesse sentido, as crianças que estão desenvolvendo alguns transtornos psiquiátricos, podem apresentar sintomas, por meio de alterações psicológicas, emocionais e comportamentais, no ambiente escolar e considerando que a criança, estará sempre sob a supervisão de um profissional da escola, comumente o professor, será mais fácil de identificar tais alterações.

Evidencia-se, portanto, que a escola é um espaço que deve atuar eficazmente na saúde mental das crianças, por meio da promoção e prevenção da saúde mental e identificação de transtornos psiquiátricos. O próximo tópicos abordar-se-á com mais ênfase sobre o assunto. 


\subsection{A SAÚDE MENTAL DA CRIANÇA NO ÂMBITO ESCOLAR}

\subsubsection{A ESCOLA}

Para González Rey e Mitjáns (2017), toda escola se configura subjetivamente em processos que se articulam, de formas diversas, às configurações subjetivas de seus membros, aos discursos dominantes de suas práticas, as representações sociais de seus diferentes processos e o tipo de funcionamento das relações sociais em seu interior. A subjetividade, como elemento integrante da cultura, encontra-se implicada nos espaços sociais da escola.

O desenvolvimento subjetivo, mediado pela cultura, assim se constitui como um fenômeno humano, sendo qualitativamente diferenciado de outros tipos de processos psíquicos. A integração do simbólico e do emocional, nesse processo, dá sentido às vivências que a pessoa experimenta em suas interrelações com os outros, com os espaços sociais, bem como os artefatos culturais e as suas ações (GONZÁLEZ REY et al., 2016). Verifica-se, portanto que, tanto os sujeitos, quanto o espaço escolar são compreendidos dentro de um sistema que funciona de forma recursiva em relação à sociedade mais ampla.

Cid et al. (2019, p.4) comentam que "a escola é um dos principais contextos de vida de crianças e adolescentes na atualidade, possuindo assim, um caráter psicossocial relevante que deve ser assumido e explorado". Verifica-se com isso que, o ambiente escolar é um espaço de surgimento de relações sociais, por isso deve ser monitorado, a fim de se evitar cenários de sofrimento e dor às crianças, pois é nas relações sociais infantis que se manifestam as primeiras inclusões e/ou exclusões sociais vivenciadas pelo indivíduo.

Sendo assim, as escolas são espaços privilegiados para a criação de ambientes favoráveis à promoção da saúde mental, estes elaborados de forma eficientes, possibilitam a produção de benefícios a longo prazo para os jovens, tanto no seu emocional quanto no social, garantindo um maior desempenho em sua vida escolar

RC: 94805

Disponível em: https://www.nucleodoconhecimento.com.br/psicologia/criancas-nocontexto 


\subsubsection{A ESCOLA E A SAÚDE MENTAL DA CRIANÇA}

Cid et al. (2019, p.2) comenta que durante o período escolar "10 a 25\% das crianças no Brasil e no mundo vivenciam a experiência do sofrimento psíquico". Tal menção enfatiza a necessidade de a escola promover ações voltadas para a saúde mental, pois é nesse espaço de aprendizado que se perceberão sintomas do adoecimento psíquico da criança. Fernandes et al. (2019, p.455) evidenciam que "o contexto escolar é uma das possibilidades de intervenção, de forma que o profissional atue como facilitador no que diz respeito ao desenvolvimento de ações de prevenção e promoção da saúde mental."

Dilleggi (2018) argumenta que a saúde mental da criança na escola pode ser influenciada por uma dinâmica familiar desestruturada, causando sofrimento as crianças que não conseguem elaborar aquela situação de desajuste relacional. Desta maneira, entende-se que a comunicação e cooperação entre a família e a escola no que tange ao acompanhamento da saúde mental são fatores imprescindíveis para o desenvolvimento positivo da criança no âmbito social, emocional e escolar. O desenvolvimento da criança depende do "compartilhamento de ideias, pela troca igualitária de valores e modos de funcionamento entre esses dois ambientes" (CID et al., 2019, p.13).

Neste contexto, a saúde mental da criança no âmbito escolar deve ser prioridade para os profissionais que atuam na escola, pois a criança psiquicamente adoecida dificilmente conseguirá ter aproveitamento nas atividades escolares. Prejuízos educacionais como perda do ano letivo, interrupção da escolarização e adoecimentos por doenças psíquicas são fatores que podem influenciar de forma negativa na adultez (FERREIRA et al., 2015). Assim, para a promoção da saúde mental na escola, Amaral et al. (2020, p.3) ressalta que "parece importante a capacitação de toda a comunidade que trata com este público-alvo, como forma de prevenir eficazmente os problemas de saúde mental, melhorando a identificação precoce e a referenciação".

RC: 94805

Disponível em: https://www.nucleodoconhecimento.com.br/psicologia/criancas-nocontexto 
Além da falta de preparação dos profissionais, cabe informar que existem alguns fatores no ambiente escolar, os quais podem abalar a saúde mental da criança, conforme veremos abaixo.

\subsubsection{BULLYING}

Um dos pontos que impacta na saúde mental da criança em ambiente escolar é a relação interpessoal com outras crianças e com os profissionais da escola. Em qualquer grupo/espaço social onde existam relações entre pessoas, é inevitável o surgimento de conflitos interpessoais os quais, quando não gerenciados, podem evoluir para situações que causem tensão e medo. Entre as questões que criam sofrimento em ambiente escolar encontra-se o bullying, normalmente ocasionados pelas diferenças entre as crianças. O bullying no ambiente escolar pode levar a exposição da "criança vítima", ocasionando deterioração, lesão e abalo psicológico, pois nessa relação de poder existem dois lados, o opressor e a vítima (LIMA, 2021).

O Bullying deve ser rechaçado pelos professores, pedagogos e psicólogos da escola, pois pode afetar diretamente a saúde mental de uma criança no ambiente escolar. Cid et al. . . (2019) comentam que a saúde mental infantil no ambiente escolar, bem como os fatores que a determinam, dependem de "ações de promoção à saúde mental das crianças, envolvendo os diferentes atores do contexto escolar (crianças, famílias, professores)" (p.20).

\subsubsection{O PROCESSO PSICOPEDAGÓGICO}

Outro fenômeno que pode abalar a saúde mental da criança é o processo psicopedagógico adotado pela escola. Silva et al. (2020) comentam que os processos psicopedagógicos das escolas, por vezes, podem criar uma dificuldade de aprendizagem na criança, desencadeando o sofrimento psíquico e abalando a sua saúde mental. Essas crianças não conseguem se adaptar as propostas pedagógicas desenvolvidas na escola, levando-as a sofrer pelo fracasso e, por 
vezes, pela "patologização" imposta pelos professores que os consideram desatentos e preguiçosos ou com algum transtorno do neurodesenvolvimento.

As ações pedagógicas realizadas pelos professores devem ser conduzidas de forma a contribuir para o desenvolvimento da aprendizagem do aluno, mas também "é essencial para tornar a escola um ambiente promotor de bem-estar e de prevenção da saúde mental" (TOMÉ et al., 2017, p. 177). Desta forma, torna-se fundamental que a escola não atribua a dificuldade de aprendizagem somente as crianças, sem antes considerar o processo de escolarização utilizado e as peculiaridades dessa criança (SILVA et al., 2020).

As escolas podem promover proteção a saúde mental dos alunos como destaca Amaral et al. (2020), desempenhando um papel proativo e de proteção, tornando-se um excelente espaço para a prevenção e promoção da saúde mental da criança durante toda a sua trajetória escolar. Por isso, as práticas pedagógicas e as ações educativas precisam estar alinhadas para não causar sofrimentos psíquicos as crianças e aos adolescentes, pois "as ações educativas devem ser integradas num contexto mais vasto de promoção da saúde das crianças" (TOMÉ et al., 2017, p. 177).

Portanto, o professor e demais profissionais da educação devem estar atentos para tais situações a fim de propor estratégias visando a promoção e prevenção da saúde mental da criança. Amaral et al. (2020, p.20), ressaltam a importância do professor neste contexto, pois é o principal ator neste cenário educacional, tendo a maior participação no processo educacional. Existe, então, a necessidade de se desenvolver políticas de intervenção voltadas a capacitação do professor na saúde mental infantil.

\subsubsection{O PROFESSOR NA SAÚDE MENTAL INFANTIL}

O professor deve ter uma preparação para levantar situações de alunos que estejam com a saúde mental abalada em face de a dificuldade em se adaptar ao processo

RC: 94805

Disponível em: https://www.nucleodoconhecimento.com.br/psicologia/criancas-nocontexto 
pedagógico da escola. Tal capacitação proporcionará melhores condições para as crianças dentro do espaço escolar. O professor deve buscar trabalhar a saúde mental da criança de forma preventiva, por meio de ações pedagógicas em sala de aula.

O professor é aquele que tem maior contato com as crianças e por isso, conhece melhor cada um de seus alunos. O professor é um elemento essencial na promoção da saúde mental do educando, pois os professores "vivenciam diariamente as situações adversas do ambiente escolar que, muitas vezes, estão relacionadas à vivência dos estudantes, tendo que lidar com as demandas acadêmicas e pessoais trazidas pelas crianças." (CID et al., 2019, p. 20).

As ações de prevenção a saúde mental da criança em ambiente escolar têm como base a observação atenta dos professores, psicólogos e psicopedagogos. Um comportamento comum, encontrado em crianças em sofrimento psíquico e que pode ser observado pelos profissionais da escola, é o isolamento ou afastamento das outras crianças. Esse sentimento de isolamento e solidão já levou muitos estudantes a apresentarem transtornos psiquiátricos, com a prevalência de ansiedade, depressão e estresse, prejudicando o desenvolvimento escolar e prejudicando a sua saúde mental (SOUZA et al., 2017). A saúde mental da criança pode ser preservada por meio de ações de prevenção e promoção, as quais devem fazer parte do plano de atividades anuais das escolas que deve se pautar em políticas de saúde mental no âmbito escolar. Portanto, "é necessário que as escolas adotem uma política de promoção da saúde mental ao longo dos anos, incluindo ambientes escolares saudáveis e com uma comunidade mais empoderada e capacitada" (AMARAL et al., 2020, p.3).

Para que a observação e julgamento seja assertiva, é necessária uma capacitação e preparação desses profissionais, pois:

As percepções dos profissionais da escola a respeito da manifestação do sofrimento psíquico remete, também, à discussão sobre o que tem sido

RC: 94805

Disponível em: https://www.nucleodoconhecimento.com.br/psicologia/criancas-nocontexto 
debatido criticamente na literatura: os critérios utilizados por profissionais da saúde e da educação para identificar "alunos-problema" que não se enquadram às regras $e$ às normas escolares e, portanto, são indiscriminadamente tidos como hiperativos, por exemplo, simplificando e reduzindo a criança e sua condição, sem considerar aspectos mais amplos que podem estar envolvidos, dentre eles o espaço escolar (CID et al., 2019, p.10).

Entretanto, deve-se mensurar a relação da criança com os diversos fatores que podem gerar sofrimento, considerando que os fatores ambientais e relações sociais contribuem para o desenvolvimento da criança. Desta forma, o isolamento radical dos fatores que produzem adoecimento mental no ambiente escolar precisa ser revisto, não somente dos alunos, mas dos profissionais que tratam com os alunos, pois são vetores de exemplo e replicação de comportamentos (COSTA-ROSA, 2019).

\subsubsection{O PSICÓLOGO ESCOLAR}

A ideia de que a escola seja um espaço multiprofissional não é nova, pois é notório que há implicações práticas entre psicologia e educação quando se trata de ambiente escolar, por isso um importante elemento para a preservação e promoção da saúde mental da criança, no ambiente escolar é o psicólogo escolar, o qual tem uma participação ativa na prevenção e promoção da saúde mental no estabelecimento de ensino, pois neste espaço podem surgir situações que produzam sofrimento psíquico no aluno, afetando a sua qualidade cognitiva e emocional, área em que o psicólogo é o profissional mais indicado para atuar (SILVA CARVALHO et al., 2021).

A presença deste profissional no ambiente escolar tem um papel fundamental na promoção e prevenção da saúde mental das crianças. Aquino (2019) comenta que o psicólogo, no contexto escolar, estrutura ações e planos para realizar intervenções com alunos, professores, famílias e gestores, traçando metas em prol dos cuidados da saúde mental. Lima $(2018$, p.4) complementa esse entendimento, argumentando 
que o psicólogo escolar é responsável pela promoção e prevenção da saúde mental no âmbito educacional e atua, juntamente com os demais profissionais de educação.

Além disso, para atuar em prol da saúde mental do aluno e comunidade escolar, seja na promoção, prevenção e intervenção, o psicólogo escolar possui ferramentas como a avaliação psicológica que podem identificar o adoecimento psíquico da criança na fase inicial. Outra forma de contribuir para a saúde mental no contexto citado é capacitar os professores na identificação de comportamento que indique o adoecimento psíquico do aluno e a sensibilização dos pais e responsáveis quanto ao cuidado da saúde mental das crianças (MELCHIORS et al., 2021). Somente com a participação de pais, professores e demais integrantes da comunidade escolar é que se conseguirá estabelecer um ambiente salutar para as crianças. Corroborando a ideia, Dias (2017) comenta que o psicólogo escolar atuará junto à comunidade escolar a fim de sensibilizar o grupo quanto a sua responsabilidade para a preservação do bem-estar daquele ambiente.

Apesar da importância do psicólogo no âmbito escolar, verifica-se que, principalmente as escolas públicas, possuem uma carência desses profissionais. Nascimento e Souza (2021) comentam que apesar de existirem debates e discussões sobre a importância do psicólogo no âmbito escolar para o ensino/aprendizagem e a saúde mental de professores e alunos, este profissional é pouco encontrado nas escolas públicas e privadas.

Constata-se, portanto, que a promoção e prevenção da saúde mental deve ser um processo, iniciado no âmbito escolar desde a pré-escola, desenvolvido a partir de ações e programas que envolvam a valorização da vida, sendo planejados e liderados pelos psicólogos e com a participação de professores e pedagogos da escola, pois a inexistência ou carência de programas voltados a prevenção e promoção da saúde mental da criança, contribui para a incidência de adoecimento psíquico infantil, prejudicando o desenvolvimento da criança (GAUY, 2016). A organização de programas psicoeducativos que despertem na criança, valores como 
fraternidade, harmonia e respeito são importantes, pois preparam a criança para enfrentar dificuldades e fortalecer a sua saúde mental dentro ou fora do espaço escolar.

A partir desta discussão, conclui-se que apesar de a escola possuir fatores que possam levar ao prejuízo da saúde mental da criança, o psicólogo escolar e demais integrantes da escola, têm uma importante atuação na promoção e prevenção a saúde mental da criança. É válido citar que ao identificar algum transtorno mental leve na criança e a equipe escolar não consiga promover a reestruturação psíquica dessa criança, deve-se procurar auxílio de profissionais e espaços específicos para o tratamento da saúde mental infantil o que será discutido no próximo tópico.

\subsection{OS ESPAÇOS DE ATENDIMENTO PSICOTERAPÊUTICOS INFANTIS}

No Brasil, políticas públicas infanto-juvenis voltadas à saúde mental na proporção psicossocial manifestaram-se apenas com a Portaria 336/2002, com a inserção de centros especializados. Em se tratando de saúde pública, existem os lugares específicos que podem tratar as crianças com problemas psíquicos originados no ambiente escolar, espaços que Agilar (2018) destaca como importantes "para cuidar da saúde mental, visando a prevenção e a promoção ao atribuir o a inclusão social dos alunos que possuem adoecimento psíquico e a sua reabilitação" (p.36). Em complemento, Fernandes et al. (2019, p.455) argumentam que "A assistência à saúde mental da infanto-juvenil deve estar pautada em algumas diretrizes de cuidado, tais como o acolhimento universal, o encaminhamento corresponsável e implicado e a construção permanente da rede e da intersetorialidade."

Tais espaços possuem profissionais e instalações adequadas para atuar com as crianças, por isso, Abranhão (2018) ressalta que, para o tratamento da saúde mental infantil existe a necessidade do conhecimento científico específico nas abordagens psicológicas e psiquiátricas. A existência de espaços especializados no tratamento 
da saúde mental infantil contribui para um atendimento qualificado e, em consequência de maior qualidade e direcionado ao paciente. Nesses casos, "o atendimento ao aluno se dá pelo acolhimento de um psicólogo que tenta descrever, prever e explicar o comportamento e os processos mentais humanos, além de ajudar a mudar e melhorar a vida dos alunos e do meio ambiente escolar que vivem" (FELDMAN, 2015, p.07).

O Sistema Único de saúde, possui uma rede específica para a saúde mental, a chamada Rede de Atenção Psicossocial (RAPs) que oferece atendimento de urgência, emergência e tratamento para transtornos mentais e dependência química. Pavani (2019, p.15) destaca que "à medida que passou a demandar uma assistência que se articulasse com outros setores, tornou-se necessária à construção de uma rede de serviços que pudesse responder demandas. Como resposta, criou-se a Rede de Atenção Psicossocial (RAPS)".

Um dos componentes desta rede que direciona o tratamento específico para crianças é o Centro de Atenção Psicossocial Infantil (CAPs-i) que são "[...] serviços de base comunitária que oferecem atenção diária a crianças e adolescentes com sofrimento mental, com prioridade aos portadores de transtornos mentais graves" (LIMA et al., 2017, p. 197). Deste modo, esses espaços são destinados especificamente às crianças e aos jovens, seguindo a estratégia da reforma psiquiátrica e a diretrizes apresentadas na Política Nacional de Saúde Mental a qual apresenta novos dispositivos de atendimentos às crianças com transtornos mentais.

Pavani (2019) define que o CAPSi se destina a assistência das crianças e adolescentes com algum transtorno mental, seja leve ou grave, bem como transtornos do neurodesenvolvimento. O CAPSi acolhe e trata de crianças e adolescentes que possuem dependência de álcool e outras drogas e todos que, por alguma questão psíquica, estejam impossibilitados ou com dificuldades de relacionar-se. O mesmo autor ainda comenta que o CAPSi "visa realizar intervenções no percurso e tratamento do sofrimento psíquico dos usuários" (p.17). 
Os espaços oferecidos para atendimento à saúde mental das crianças são reduzidos em opções e quantidade de espaços. Por isso, reforça-se assim, a necessidade de políticas públicas mais eficientes, buscando atender eficazmente as necessidades quanto a saúde mental infantil no meio social e escolar, pois é neste último que a criança vivenciará novas relações e dificuldades que poderão influenciar no seu desenvolvimento como indivíduo.

\section{CONSIDERAÇÕES FINAIS}

A escola é uma instituição diligente e complexa, responsável historicamente pela educação formal do indivíduo. Contudo, observou-se que é neste espaço que o indivíduo vivencia diversas situações que contribuem para a construção da sua personalidade. Neste espaço também, há manifestação de diversas necessidades de se aprender.

Verifica-se que a escola é um espaço de construção do indivíduo e um local para estabelecimento das primeiras relações interpessoais da criança. $O$ ambiente escolar, propicia condições de observação e acompanhamento do desenvolvimento das crianças, bem como o acompanhamento da sua saúde física e mental. A escola, por meio do seu quadro de profissionais capacitados para tal, pode atuar, com eficiência, na promoção e prevenção da saúde mental das crianças, além de auxiliar na identificação de sintomas que levem a suspeita de algum transtorno psiquiátrico leve. Entretanto, verifica-se que esta prática não é adotada por todas as escolas, deixando a possibilidade do surgimento de transtornos psiquiátricos devido a problemas como bullying.

Constata-se, por essa pesquisa, que para a escola atuar na saúde mental da criança necessita de um quadro de profissionais para conduzir ações que visem promover saúde mental e prevenir o surgimento de transtornos psiquiátricos nas crianças, considerando que as crianças estão vivenciando uma fase da vida onde ainda possuem dificuldade de tratar com suas emoções. 
Por fim, entende-se que, apesar de existirem políticas públicas sobre o assunto, essas não são efetivamente aplicadas, deixando um hiato nas ações voltadas a promoção e prevenção relacionados a saúde mental da criança. Desta forma, entendendo que existe muito a ser feito a respeito da saúde mental da criança no âmbito escolar, este estudo torna-se apenas um esboço do tema que merece mais investigações para desenvolver um trabalho em prol da saúde mental infantil.

\section{REFERÊNCIAS}

ABRANHÃO, L. Promoção da vida: cuidando dos indivíduos e mudando as sociedades, todos suicídios são evitáveis. Porto Alegre: Secco, 2018.

AGILAR, K.J.S. Novas intervenções psicológicas na saúde mental. 2018. $40 f$. Trabalho de Conclusão de Curso (graduação em psicologia) - Faculdade da Amazônia, Vilhena/RO, 2018. Disponível em: http://repositorio.famaro.com.br/handle/123456789/119. Acesso em 12 mar. 2021.

AGUIAR, B.M. Similaridades e Diferenças de Crianças/Cuidadores Atendidos em Serviço-Escola de Psicologia e Psiquiatria. Psico-USF, Bragança Paulista, v. 23, n. 1, p. 109-125, jan./mar. 2018. Disponível em: http://dx.doi.org/10.1590/141382712018230110. Acesso em 15 mar. 2021.

AMARAL, M.O.P. et al.. ProMenteSã: Formação de professores para promoção da saúde mental na escola. Acta Paulista de Enfermagem, São Paulo, v. 33, p.1-8. 2020. Disponível em:https://acta-ape.org/wp-content/uploads/articles_xml/19820194-ape-33-eAPE20190224/1982-0194-ape-33-eAPE20190224.pdf. Acesso em 12 mar. 2021.

AQUINO, A. R. O Trabalho da (o) Psicóloga (o) e a Educação Inclusiva. Revista Anais da Semana de Licenciatura, Jataí, v. 1, n.1, p.130-142. 2019. Disponível em: https://1library.org/document/ynl958jq-o-trabalho-da-o-psicologa-o-educacaoinclusiva.html. Acesso em 10 mar. 2021. 
CID, M.F.B et al.. Saúde mental infantil e contexto escolar: as percepções dos educadores. Pro-Posições, Campinas, v.30, p.124, 2019. Disponível em: https://periodicos.sbu.unicamp.br/ojs/index.php/proposic/article/view/8656529. Acesso em 15 mar. 2021.

CID, M.F.B.; MATSUKURA, T.S. Problemas de saúde mental em escolares e seus responsáveis: um estudo de prevalência. Revista de Terapia Ocupacional da Universidade de São Paulo, São Paulo, v. 25, n. 1, p. 1-10, 2014. Disponível em: https://www.revistas.usp.br/rto/article/view/56173/87283. Acesso em 10 mar. 2021.

D'ABREU, L.C.F.; MARTURANO, E.M. Associação entre comportamentos externalizantes e baixo desempenho escolar: uma revisão de estudos prospectivos e longitudinais. Estudos de Psicologia, Maringá, v.15, n.1, p.43-51. 2010. Disponível em: https://www.scielo.br/j/epsic/a/BycfsR6kzcfrZfy7Dx3bmfR/abstract/?lang=pt. Acesso em 11 mar. 2021.

COSTA-ROSA, A. Intercessões e análises sobre o Processo de Produção saúdeadoecimento-Atenção no campo psíquico, num Território municipal. Revista de Psicologia da UNESP, São Paulo, v.18 (especial), p. 9-36. 2019. Disponível em: https://seer.assis.unesp.br/index.php/psicologia/article/view/1541/1351. Acesso em 12 mar. 2021.

DE SOUZA M.S.; BAPTISTA, M.N. Associações entre suporte familiar e saúde mental. Psicologia Argumento, Curitiba, v. 26, n. 54, p. 207-215, 2017. Disponível em: $\quad$ https://biblat.unam.mx/hevila/Psicologiaargumento/2008/vol26/no54/3.pdf. Acesso em 10 mar. 2021.

DELGADO, P.G.G.; GOMES, P.C.; COUTINHO, E.S.F. Novos rumos nas políticas públicas de saúde mental no Brasil. Cad. Saúde Pública. Rio de janeiro (Editorial) v.17, n.3, p.452-453. 2001. Disponível em: https://www.scielo.br/j/csp/a/s87BC9WyGrL8x7PKMxt3vBJ/?format=pdf\&lang=pt. Acesso em 10 mar. 2021.

RC: 94805

Disponível em: https://www.nucleodoconhecimento.com.br/psicologia/criancas-nocontexto 
DENZIN, N.K.; LINCOLN, Y.S. O planejamento da pesquisa qualitativa: teorias e abordagens. Porto Alegre: Artmed, 2006.

DIAS, C. N. et al.. Psicologia na escola e rede de proteção à infância e adolescência: enfrentando vulnerabilidades. 2017. 185 f. Dissertação (mestrado em psicologia) - Pontifícia Universidade Católica, Campinas, 2017. Disponível em: http://tede.bibliotecadigital.puc-

campinas.edu.br:8080/jspui/bitstream/tede/944/2/CAROLINA\%20NASCIMENTO\%20 DIAS.pdf. Acesso em 11 mar. 2021.

DILLEGGI, E.S. Funcionamento familiar e recursos ambientais oferecidos pelas famílias de crianças com transtornos mentais. 2018. 105 f. Dissertação. (Mestrado em enfermagem psiquiátrica) Universidade de São Paulo, São Paulo. 2018. Disponível em: https://teses.usp.br/teses/disponiveis/22/22131/tde-05122018204947/pt-br.php. Acesso em 12 mar. 2021.

FELDMAN, R.S. Introdução a psicologia. 10. ed. Porto Alegre: Artmed, 2015.

FERNANDES, A.D.S.A et al.. A intersetorialidade no campo da saúde mental infantojuvenil: proposta de atuação da terapia ocupacional no contexto escolar. Cadernos Brasileiros de Terapia Ocupacional, v. 27, p. 454-461, 2019. Disponível em: https://www.scielo.br/j/cadbto/a/k86SYLnVLpVgzbJZr7N8y3p/abstract/?lang=pt. Acesso em 11 mar. 2021.

FERREIRA, M.K.M. et al.. Criança e adolescente cronicamente adoecidos e a escolarização durante a internação hospitalar. Trabalho, Educação e Saúde, v. 13, n. $3, \quad$ p. 639-655, 2015.2 Disponível em: https://www.scielo.br/j/tes/a/dhMxnn6JmV5SXmyjd4JVkgm/?lang=pt. Acesso em 14 mar. 2021. 
GAINO, L.V. et al.. O conceito de saúde mental para profissionais de saúde. Revista Eletrônica Saúde Mental Álcool e Drogas, v. 14, n. 2, p. 108-116, 2018. Disponível em: http://pepsic.bvsalud.org/pdf/smad/v14n2/07.pdf. Acesso em 15 mar. 2021.

GAUY, F.V. Crianças e adolescentes com problemas emocionais e comportamentais têm necessidade de políticas de inclusão escolar? Educar em Revista. n. 59, p. 7995. 2016. https://doi.org/10.1590/0104-4060.44687. Acesso em 12 mar. 2021

GIL, A.C. et al.. Como elaborar projetos de pesquisa. 4. ed. São Paulo: Atlas, 2007.

GONZÁLEZ REY, F. et al. . Psicología en la Educación: implicaciones de la subjetividad en una perspectiva Cultural Histórica. Revista Puertorriqueña de Psicología. v. 27, n. 2, p. 260 - 274, jul./dez. 2016. Disponível em: http://www.ojs.repsasppr.net/index.php/reps/article/view/290/0. Acesso em 12 mar. 2021.

GONZÁLEZ REY, F; MITJÁNS, M. El desarrollo de la subjetividad: una alternativa frente a las teorías del desarrollo psíquico. Papeles de Trabajo sobre Cultura, Educación y Desarrollo Humano, v.12, n.2, p. 3-20. 2017. Disponível https://dialnet.unirioja.es/servlet/articulo?codigo=6026205. Acesso em 13 mar. 2021.

INSTITUTO AGENDA POSITIVA. Cuidando da Saúde Mental. 2020. Disponível em: https://agendapositiva.org.br/artigo/cuidando-da-saude-mental. Acesso em 13 mar. 2021.

LIMA, R.C. et al.. Atenção psicossocial a crianças e adolescentes com autismo nos CAPSi da região metropolitana do Rio de Janeiro. Saúde e Sociedade, v. 26, p. 196-207, 2017. Disponível em https://www.scielosp.org/pdf/sausoc/2017.v26n1/196207/pt. Acesso em 12 mar. 2021.

RC: 94805

Disponível em: https://www.nucleodoconhecimento.com.br/psicologia/criancas-nocontexto 
LIMA, C. M. et al.. Promoção da saúde mental e enfrentamento ao bullying no ambiente escolar. Research, Society and Development, v. 10, n. 5, p. 1-6. 2021. Disponível em: http://dx.doi.org/10.33448/rsd-v10i5.14692. Acesso em 12 mar 2021.

LIMA, Maysa dos Santos de. Psicologia escolar: a promoção da saúde mental na escola. 2018. 27 f. Trabalho de conclusão de curso (licenciatura em Pedagogia) -, Instituto de Biociências, Universidade Estadual Paulista Júlio de Mesquita Filho, Rio Claro. 2018. Disponível em: http://hdl.handle.net/11449/203435. Acesso em 4 ago. 2021.

MATSUKURA, T.S.; CID, M.F.B. Intervenção junto a professores do ensino público municipal: abordando os papéis da família e escola no desenvolvimento infantil e viabilizando ações. In: ARAÚJO FILHO, T.; THIOLLENT, M. (Orgs.), Metodologia para projetos de extensão: apresentação e discussão. São Carlos: Cubo multimídia. 2008. p. 192-196.

MELCHIORS, Luciane et al. . Psicologia no contexto escolar: possíveis intervenções com adolescentes na prevenção ao suicídio. p.176-185. 2021. Disponível em: https://downloads.editoracientifica.org/articles/201001910.pdf. Acesso em 4 ago. 2021.

NASCIMENTO, D.A.; SOUZA, J.C.P. A percepção dos professores de uma escola pública quanto a necessidade de um psicólogo escolar. Revista EDUCAmazônia Educação Sociedade e Meio Ambiente, Manaus, v. XIII, n. 2, p. 228252.jul/dez.2021.

ORGANIZAÇÃO MUNDIAL DE SAÚDE. Constituição da Organização Mundial da Saúde. 2017. Disponível em: http://www.direitoshumanos.usp.br/index.php/OMSOrganiza\%C3\%A7\%C3\%A3o-Mundial-da-Sa\%C3\%BAde/constituicao-daorganizacao-mundial-da-saude-omswho.html. Acesso 13 mar. 2021. 
PAVANI, F.M. Avaliação das práticas em saúde mental voltadas às adolescências em um centro de atenção psicossocial infanto-juvenil. 2019. Dissertação (Mestrado em Enfermagem) Universidade Federal do Rio Grande do Sul, Porto $\quad$ Alegre. 2019. Disponível em: https://www.lume.ufrgs.br/handle/10183/201739. Acesso em 14 mar. 2021.

SANTOS, R.G.H.; CELERI, E.H.R.V. Rastreamento de problemas de saúde mental em crianças pré-escolares no contexto da atenção básica à saúde. Rev Paul Pediatr. São Paulo, v. 36, n.1, p. 82-90. 2018. Disponível em https://www.scielo.br/j/rpp/a/4KkpDYvkQxJt579KmcpHmqp/?lang=pt. Acesso em 15 mar. 2021.

SILVA CARVALHO, Gabrieli et al.. A saúde mental dos adolescentes em contexto escolar. In: CONGRESSO INTERNACIONAL DE PSICOLOGIA, I, Cachoeiro do Itapemirim. Anais [...]. Cachoeiro do Itapemirim: UNIFACIG, 2021. do I Congresso Internacional de Psicologia da Faculdade América. 2021.p. 1-5. Disponível em: http://pensaracademico.facig.edu.br/index.php/congressointepsicologiafamerica/articl e/view/2695/2046. Acesso em 4 ago. 2021.

SILVA, N.T.L. Promoção da saúde mental na escola e os desafios dos laudos emitidos pelo capsi para justificar os entraves à aprendizagem. Revista Docentes. Fortaleza, v.5, n.11, p. 65-75. 2020. Disponível em: https://revistadocentes.seduc.ce.gov.br/index.php/revistadocentes/article/view/221. Acesso em 15 mar. 2021.

SOUZA. M.R. et al.. Fatores de adoecimento dos estudantes da área da saúde: uma revisão sistemática. Psicologia e Saúde em Debate. v. 3, n. 1, p. 99-126, 2017. Disponível em: http://psicodebate.dpgpsifpm.com.br/index.php/periodico/article/view/93. Acesso em 12 mar. 2021. 
TREINTA, F. et al.. Metodologia de pesquisa bibliográfica com a utilização de método multicritério de apoio à decisão. Production, Niterói/RJ, v. 24, n. 3, p. 508520, jul/set. 2014.2 Disponível em: https://www.scielo.br/j/prod/a/9BprB4MFDXfpSJqkL4HdJCQ/. Acesso em 10 mar. 2021.

TOMÉ, Gina Maria Quinás et al.. Promoção da saúde mental nas escolas: Projeto ES' COOL. Revista de Psicologia da Criança e do Adolescente, Lisboa/Portugal, v.8, n.1, p. 173-184. 2017. Disponível em: https://repositorio.ul.pt/bitstream/10451/38430/1/ES_COOL.pdf. Acesso em 12 mar. 2021.

Enviado: Junho, 2021.

Aprovado: Agosto, 2021. 